\title{
DROMTOS
}

Revista de Comunicación Digital

\section{Personalización, transversalidad y capilaridad: la campaña digital del BNG para las Elecciones Gallegas de 2020}

\section{Personalisation, transversality and capillarity: the BNG's digital campaign for the Galician Elections 2020}

\author{
Rubén Rivas-de-Roca \\ rrivasderoca@us.es \\ Universidad de Sevilla
}

\section{Resumen}

La crisis del COVID-19 no solo modificó la fecha de los comicios previstos en País Vasco y Galicia, sino que transformó su marco comunicativo. En el caso de las Elecciones al Parlamento de Galicia de 2020, los resultados reflejan un importante cambio en la configuración de la oposición. El nacionalismo cosechó la mejor representación de su historia de la mano del Bloque Nacionalista Galego (BNG), a la vez que se produjo la desaparición parlamentaria de la izquierda rupturista.

Teniendo esto en cuenta, el objetivo de esta investigación es analizar la campaña desarrollada en redes sociales (Facebook, Twitter e Instagram) por el BNG y su líder Ana Pontón, en el sentido de si expusieron estrategias innovadoras que conectaran con la juventud. Este público ha sido el principal votante del BNG de acuerdo con estudios postelectorales. Para lograr ese propósito se lleva a cabo un análisis de contenido que estudia los temas tratados en la campaña. También se valora el impacto cuantitativo en la fase de contienda electoral y los formatos empleados, en esta ocasión a través de un enfoque cualitativo.

Como resultado se aprecia una agenda temática plural. La campaña adopta rasgos de personalización política, en la figura de Ana Pontón; transversalidad y flexibilidad, al dejar atrás postulados soberanistas; y capilaridad, con un notable peso de las agrupaciones locales. Todas esas estrategias han sido tradicionalmente propias del Partido Popular de Galicia (PPdeG), si bien el BNG semeja aplicarlas buscando nichos de votantes juveniles. El caso analizado demuestra cómo un partido clásico se apropia del espacio digital de la "nueva política", consiguiendo erigirse en líder de la oposición en un contexto de desmovilización por la pandemia.

\section{Palabras clave}

Comunicación política; estrategia electoral; campañas digitales; Elecciones Gallegas; BNG.

Edita: Miguel Vicente-Mariño

Recibido: $27 / 11 / 2020$

Aceptado: 22/03/2021

Cómo citar este artículo:

Rivas-de-Roca, R. (2021). Personalización, transversalidad y capilaridad: la campaña digital del BNG para las Elecciones Gallegas de 2020. Dígitos. Revista de Comunicación Digital, 7: 91-112. DOI: 10.7203/rd.v1i7.199 


\begin{abstract}
The COVID-19 crisis did not only change the date of the regional elections in the Basque Country and Galicia, but it has also transformed their communication framework. In the case of the Galician elections in 2020, the results show a major modification in terms of opposition. Nationalism got the best representation of its history thanks to BNG (Bloque Nacionalista Galego), at the same time that left-wing populism lost all its seats in the parliament. Keeping this special context in mind, this research examines the campaign developed on social networks (Facebook, Twitter and Instagram) by the BNG and its leader Ana Pontón, in the sense of whether they presented innovative strategies to better connect with the youth. This public was the main voter of the BNG in 2020 according to post-electoral surveys. To achieve this purpose, a content analysis is carried out on the topics discussed during the campaign. The quantitative impact on the electoral contest and the ways of expression are also assessed through a qualitative approach. As a result, we found a plural thematic agenda. The campaign of the BNG adopts several features: political personalization with Ana Pontón; cross-cutting political cleavages by leaving behind independence messages; and capillarity through a huge number of local groups. All these strategies have traditionally overlapped with the PPdeG (Partido Popular de Galicia). However, the BNG uses them to look for young voters. The case analyzed reveals how a classic party appropriates the digital space of the "new politics", managing to become the leader of the opposition in a context of demobilization due to the pandemic.
\end{abstract}

\title{
Keywords
}

Political communication, social networks, TikTok, Instagram, Gab, Vox

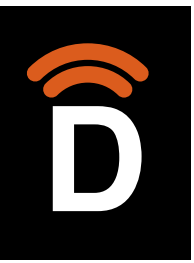

La comunicación política de la derecha radical en redes sociales. De Instagram a TikTok y Gab, la estrategia digital de Vox

\section{Introducción}

Las Elecciones al Parlamento de Galicia de 2020 se vieron afectadas por la pandemia de Covid-19, que aplazó tres meses su celebración y alteró el marco comunicativo en una comunidad marcada políticamente por la estabilidad de las mayorías absolutas del Partido Popular de Galicia (PPdeG). Los resultados de los comicios supusieron una nueva mayoría de la formación conservadora, pero se produjeron importantes cambios en la oposición, alcanzando el Bloque Nacionalista Galego (BNG) su techo electoral en número de escaños (19) tras obtener su mínimo de representación (6) en las anteriores elecciones de 2016.

Los 311.340 votos cosechados por el BNG lo convirtieron en el primer partido de la oposición, algo que solo había sucedido antes en el período 1997-2001. El nacionalismo gallego, con una trayectoria llena de momentos en la marginalidad (Gómez-Reino, 2009), consiguió así establecerse como la principal alternativa al PPdeG. Se trata además de un resultado que rompe el distanciamiento entre el BNG y las preferencias de los votantes, creciente desde 2005 (Warf y Ferras, 2015; Ares, 2017). El BNG parece haber conseguido en 2020 adaptarse a la lógica transversal del electorado gallego (Ares y Rama, 2019), clave en las mayorías populares, pero también en las consolidadas 
alcaldías nacionalistas en territorios tan dispares como Allariz (Ourense), Fene (A Coruña) o la ciudad de Pontevedra (Lois Barrio, 2007).

El nacionalismo gallego sustituyó en la década de los noventa el paradigma antiespañolista, dominante en la Unión do Povo Galego (UPG) - partido comunista e independentista central en el seno del BNG_, por el llamado "proyecto común", orientado a las políticas sociales por encima del debate soberanista (Máiz, 2003). Estos planteamientos llevaron en el año 2005 al Bloque por primera vez al gobierno de la Xunta de Galicia (Gómez-Reino, 2009), en forma de coalición con el Partido Socialista de Galicia (PSdeG). Sin embargo, la derrota electoral de 2009 en un contexto de crisis económica e incipiente crisis territorial en España llevó al BNG de vuelta al eje centro-periferia, situándolo porcentualmente en la marginalidad política, mientras el descontento social era acaparado por opciones bimodales entre el galleguismo y la izquierda rupturista como las "Mareas".

La campaña desarrollada por el BNG en 2020, centrada en la figura política de Ana Pontón y la necesidad de poner en marcha una nueva Galicia (Unha nova Galiza) ante la emergencia del Covid-19, puede suponer un regreso al "proyecto común". No obstante, el éxito electoral fue mayor que el cosechado en 1997, erigiéndose el BNG en el partido más votado en la franja de edad situada entre 18 y 24 años (La Voz de Galicia, 2020). Por ello, el objetivo de esta investigación es conocer la campaña digital del BNG y su líder Ana Pontón en redes, tratando de ahondar en las posibles estrategias que conectaron con la juventud. Cabe mencionar que quizás esta apuesta por las redes sociales pueda ser valorada como una decisión estratégica, puesto que la formación contaba con menor financiación tras sus últimos malos resultados electorales.

Las Elecciones al Parlamento de Galicia tuvieron lugar durante la pandemia de Covid-19, que ha producido una situación de desinformación, calificada como "infodemia" (Aleixandre-Benavent, Castelló-Cogollos y Valderrama-Zurián, 2020), en la que resulta imprescindible que la clase política transmita liderazgo y confianza (de Blasio y Selva, 2020). Asimismo, la obligada distancia social abre nuevas vías a la ciberpolítica, como es el caso de las campañas personalizadas que apelan a comunidades pequeñas a través de las nuevas tecnologías (Dader, 2017). Los procesos electorales llevan tiempo marcados por la mediatización (Mazzoleni, 2010; Esser y Strömbäck, 2014) y las redes sociales (Chavero, 2013; Campos-Domínguez, 2017), pero la emergencia sanitaria puede haber acelerado estas tendencias.

Por otro lado, la centralidad de la campaña en torno a Ana Pontón imbrica con la personalización de la política en la era digital (McAllister, 2007), a pesar de que el panorama político gallego sigue marcado por la identificación territorial, absorbida hasta ahora por el PPdeG (Ares y Rama, 2019). Esa necesidad de combinar agendas para el BNG, junto con su buen resultado electoral en una situación de desmovilización general a causa de la pandemia, justifican el interés en efectuar esta investigación. Se pretende evaluar además la asimilación de prácticas digitales entre los partidos y los movimientos sociales, detectada por la literatura (Sánchez Duarte y Magallón Rosa, 2020). Establecer vínculos ente las actuaciones comunicativas y los datos electorales es complejo, de ahí que este artículo gire en torno al objetivo de profundizar sobre una campaña que tuvo lugar en tiempos de Covid-19. 


\section{Antecedentes teóricos}

\subsection{Un nacionalismo en construcción: del centro-periferia a la mayoría galeguista}

El nacionalismo gallego tiene sus raíces históricas en el siglo XIX, momento en el que se produce una toma de conciencia sobre una etnicidad lingüística diferencial en un territorio homogéneo que sufría un déficit institucional por su temprana incorporación a las coronas castellanas, al contrario de lo sucedido con el País Vasco o Cataluña (Máiz, 1996). Los mitos fundacionales del nacionalismo gallego se vinculan con el Rexurdimento, un movimiento literario de revitalización de la lengua gallega. Esta etapa cultural de corte romanticista fue similar a las que caracterizaron a la primera ola de movilización nacionalista en Europa (Núñez Seixas, 2001).

La génesis literaria de la identidad gallega explica el peso de la obra de Rosalía de Castro en su construcción, como máxima exponente del idioma, así como de su marido, Manuel Murguía, creador de la Real Academia Gallega (RAG) y autor de Historia de Galicia, pieza central de la historiografía gallega. Pese a este impulso cultural que sienta las bases de una conciencia común, el nacionalismo gallego fracasa en su intento de organizarse políticamente durante el siglo XIX (Máiz, 1996). No es hasta el siglo XX, primero con As Irmandades da Fala (1916-1931) y luego con el Partido Galeguista (19311950), cuando el nacionalismo transita del plano cultural al de la política, presidido por Castelao (Núñez Seixas, 2001).

El centralismo de la dictadura franquista provoca un giro hacia el antiespañolismo por parte del nacionalismo gallego en el exilio, del cual bebe UPG, organización marxistaleninista fundada en 1964 que acapara buena parte del movimiento y que es clave en la creación del BNG como coalición en 1982. Por tanto, el nacionalismo gallego inició el período democrático con una visión anticolonial de España, alejada de los postulados mayoritarios en Galicia y que le impidió desempeñar un rol relevante en la configuración autonómica (Elias, 2009).

El proceso de transición desde la marginalidad política al poder vino marcado por la adopción del denominado "proyecto común" a principios de la década de 1990, que defendía los intereses de la clase obrera de Galicia por encima de las cuestiones nacionales (Máiz, 2003). El BNG se consolidó como una formación fuertemente enraizada con el territorio (Warf y Ferras, 2015), caracterizándose por su capilaridad a través de una amplia implantación territorial, singularmente municipal (Lois Barrio, 2007). El éxito de esta estrategia radica en el peso de la identificación geográfica y la lengua propia - usada siempre por el BNG - para la población, aunque no sea gallegoparlante (Ares, 2017). De hecho, según el CIS (2020) el 64,7\% de los ciudadanos de la comunidad se siente tan español como gallego y un $18,6 \%$ más gallego que español, mientras que el porcentaje de encuestados que sitúa a España por encima apenas llega al $4 \%$.

El PPdeG es el partido que ha acaparado tradicionalmente los ámbitos ideológico y territorial (Ares y Rama, 2019), mediante un galleguismo moderado y una defensa de la identidad regional, visible en el lema de campaña "Galicia, Galicia, Galicia" de su candidato Alberto Núñez Feijóo para los comicios de 2020, que ocupa el puesto de presidente de la Xunta de Galicia. Frente a ello, la tercera ola de movilización nacionalista dio señales de agotamiento en 2009, coincidiendo la salida del BNG del poder con la 
crisis económica y la emergencia de movimientos independentistas tanto en España como en Europa, siendo Cataluña y Escocia ejemplos paradigmáticos.

En este contexto, el BNG viró de nuevo su estrategia de competición electoral hacia el eje centro-periferia (Ares, 2017), implementando un marco frentista entre nacionalismo y españolismo que se alineaba con el independentismo catalán. Sin embargo, los resultados de 2012 y 2016 sumieron al nacionalismo gallego en la irrelevancia, a la vez que los buenos datos de Alternativa Galega de Esquerda (AGE) y luego En Marea ambas próximas al entorno de Podemos incluso antes de su nacimiento- evidenciaron un desplazamiento electoral al eje ideológico.

La crisis del BNG tuvo como punto de inflexión en febrero de 2016 la llegada a la portavocía nacional de Ana Pontón, la primera mujer en ocupar ese cargo en un partido al que se le achacaba un excesivo ruralismo (Espinosa y Lema, 2020). La nueva líder optó por rejuvenecer y feminizar el partido, consiguiendo mantener la representación parlamentaria ese año. En la cita autonómica de 2020 este fenómeno se aceleró, contando con tres cabezas de lista mujeres en las cuatro provincias gallegas. Además, dos de ellas (Noa Presas en Ourense y Olalla Rodil en Lugo) no superaban los 35 años.

En cuanto a oferta programática, el BNG de Pontón ha aproximado su estrategia a los votantes, apelando a la mayoría galleguista (Varela y Placer, 2020). El partido ha conectado además con movimientos culturales previos como los neofalantes (nuevos hablantes), que promueven en redes sociales el uso del gallego entre los más jóvenes (O'Rourke y Ramallo, 2015). Estas prácticas se realizan en un momento de política digital, en el que la juventud se revela especialmente sensible a la movilización social y medioambiental en Internet (Toret, 2013; Rivas-de-Roca, 2020). Ante esto, los candidatos se ven obligados a desarrollar encuadres partidistas en una gran variedad de formatos (Valera Ordaz, Carratalá Simón y Palau Sampio, 2017).

En las Elecciones al Parlamento de Galicia de 2012 se observó por primera vez la irrupción de un movimiento rupturista en el plano de la comunicación política, de la mano de Alternativa Galega de Esquerdas. Esta agrupación, que aunaba a Esquerda Unida (EU) y Anova, empleó las redes sociales, y en particular Twitter, de una manera masiva y espontánea (Fernández-Cabana, Rúas-Araújo y Alves-Pérez, 2014), lo que se conjugaba con la presencia de su líder en medios tradicionales (Blanco Casais, 2013). Su éxito electoral, superando al BNG, puso de manifiesto las dificultades iniciales de esta formación para adaptar su mensaje al contexto digitalizado (Máiz y Ares, 2018).

Como se ha comentado, el último cambio ideológico del BNG puede situarse en 2016, año en el que se desarrollaron de nuevo comicios autonómicos, evidenciando todos los líderes una preferencia por cuestiones económicas y materiales en sus campañas (López-López, Puentes-Rivera y Rúas-Araújo, 2017). Las referencias al autogobierno gallego quedaron diluidas, si bien fue en las fuerzas vinculadas a la izquierda y el nacionalismo, como En Marea y el BNG, en las que se experimentó una mayor pluralidad de recursos comunicativos en redes dirigidos a la ciudadanía (Morales López y Montesano Montessori, 2019), frente a un cierto inmovilismo del PPdeG y el PSdeG.

\subsection{Las Elecciones al Parlamento de Galicia de 2020: comunicación política en tiempos de pandemia}

La pandemia causada por el Covid-19 modificó el marco comunicativo dela comunicación 
política en 2020, incluyendo las elecciones que habían de celebrarse durante ese año. Este es el caso de los comicios gallegos, que se trasladaron del 5 de abril al 12 de julio. La emergencia sanitaria generó una ola de desinformación (Aleixandre-Benavent, Castelló-Cogollos y Valderrama-Zurián, 2020; Nielsen et al., 2020), que requirió una acción comunicativa fiable y efectiva por parte de los políticos (de Blasio y Selva, 2020). Por ende, los ciudadanos exigieron que sus dirigentes transmitieran confianza, lo que pudo afectar al devenir de los procesos electorales previstos.

El Covid-19 constituye una muestra de elemento disruptivo que amenaza la participación electoral (Blais et al., 2004), ya que las posibilidades de contagio en el contacto social coartarían a los ciudadanos de acudir a votar. Esto resulta de especial interés con los jóvenes convocados a las urnas por primera vez e identificados como objeto del BNG, dado que el comportamiento en las elecciones iniciales de su vida va a determinar su voto posterior (Schäfer, Roßteutscher y Abendschön, 2020). El ambiente de desconfianza política en España a raíz de la pandemia, semejante a la noción de "contrademocracia" (Rosanvallon, 2007), ocasiona que sea aún más importante que los políticos de proximidad contribuyan a la estabilidad de las esferas local y regional (Jenkins y Nielsen, 2020).

Por su parte, el distanciamiento obligado refuerza la relevancia de la comunicación digital en los procesos electorales. Este peso creciente de las tecnologías había conducido ya en los últimos años a una profesionalización de la política en Estados Unidos y Europa occidental (Tenscher et al., 2016), que trasciende de eventos sociales como mítines o encuentros con simpatizantes. La literatura sostiene que la comunicación política actual posee una naturaleza híbrida, en la que la lógica mediática de los actos físicos y los medios tradicionales se conjuga con las herramientas digitales (Chadwick, 2013; Vaccari y Valeriani, 2015).

Las redes sociales desempeñan un papel fundamental para los candidatos en campaña, hasta el punto de suponer el espacio central de construcción partidista (Jungherr, 2016). Twitter es la red social que por sus rasgos de microblogging mejor se adapta al panorama informativo (López-Meri, Marcos-García y Casero-Ripollés, 2017), con enormes posibilidades para dar a conocer a actores marginales (Enli, 2017), como podría ser el nacionalismo gallego entre 2016-2020. En cualquier caso, Facebook e Instagram también han demostrado su valía para la comunicación política, referente a la discusión pública (Valera-Ordaz, 2019) y a la popularización de figuras individuales (Lalancette y Raynauld, 2019), respectivamente.

La proliferación de las tecnologías digitales ha espoleado el citado carácter bimodal de la mediatización, un fenómeno asentado desde finales del siglo XX que consiste en que los ciudadanos comprenden los asuntos políticos a través del prisma de los medios de comunicación, o más recientemente mediante las plataformas digitales (Esser y Strömbäck, 2014). En consecuencia, los eventos televisivos como los debates han evolucionado hacia un modelo multipantalla (Pérez-Curiel y García-Gordillo, 2020; RúasAraujo y Quintas-Froufe, 2020), de influencia mutua entre las cadenas convencionales y las redes sociales.

A pesar de la revolución digital, los debates electorales mantienen una relativa importancia para reforzar el voto (Lagares Diez, Jaráiz Gulías y Castro Martínez, 2020), en el seno de una personalización de la política también impulsada por las nuevas tecnologías (Rodríguez- 
Virgili, Jandura y Rebolledo-de-la-Calle, 2014). Estas personalidades políticas con presencia en la Red funcionan muchas veces como fuentes de información periodística (Lecheler y Kruikemeier, 2016). Hay investigaciones que señalan que la gestión comunicativa de estos actores en España prioriza la hibridación mediática, dotada de una excesiva autorreferencialidad (García-Ortega y Zugasti-Azagra, 2018).

Las elecciones autonómicas apenas han sido abordadas como objeto de estudio diferenciado, con algunas excepciones que subrayan que no hace falta aplicar una política de comunicación proactiva para convertirse en el centro de atención de la campaña (Marín Dueñas y Díaz Guerra, 2016; Rivas-de-Roca, García-Gordillo y Bezunartea-Valencia, 2020). Entra aquí en juego el efecto bandwagon, por el cual la audiencia puede sumarse a una corriente política emergente (Mañas Ramírez, 2013), lo que en nuestro trabajo se dirigiría a evaluar si el BNG operó como tal en las Elecciones al Parlamento de Galicia de 2020.

\section{Metodología}

El objetivo de esta investigación es analizar la campaña electoral efectuada en redes sociales por el BNG y su líder Ana Pontón en las Elecciones al Parlamento de Galicia de 2020, en tanto que consiguieron una histórica representación en un momento extraordinario por la pandemia de Covid-19. Partiendo de la revisión teórica se identifican a la personalización, la transversalidad y la capilaridad en grupos locales como posibles hilos conductores de la campaña, por lo que se fijan las siguientes preguntas de investigación para orientar el presente estudio:

PI1. ¿Cuáles son los temas tratados por el BNG y Ana Pontón en redes sociales?

PI2. ¿De qué calibre es el impacto cuantitativo de los mensajes distribuidos en Internet?

PI3. ¿Qué estrategias comunicativas diferenciadas se aplican en cada red social?

PI4. ¿Cómo se articulan discursivamente los principios de personalización, transversalidad y capilaridad?

Para responder a dos primeras cuestiones formuladas se aboga por el análisis de contenido, cuya capacidad de creación de categorías resulta especialmente útil para el área de comunicación (Igartua, 2006). En nuestro caso se lleva a cabo sobre los mensajes en las tres principales redes sociales: Facebook, Twitter e Instagram. Los datos se recogen mediante una ficha de análisis para asuntos temáticos, desarrollada ad hoc para este estudio basándonos en una observación de los issues más mencionados en los principales medios impresos gallegos ( La Voz de Galicia y Faro de Vigo durante junio de 2020).

La propuesta metodológica ha sido materializada por un único codificador, puesto que las categorías temáticas no presentan un grado de ambigüedad tan elevado como otras variables. No obstante, se realizaron dos sesiones de entrenamiento con otro investigador del área sobre el 5\% de la muestra, añadiendo nuevas normas de codificación para que la descripción de las categorías funcionara de manera excluyente (ver Tabla 1). Esta metodología aplica una observación de los mensajes de campaña, basada en estudios previos sobre la agenda temática en comicios autonómicos (LópezLópez, Puentes-Rivera y Rúas-Araújo, 2017; Rivas-de-Roca, García-Gordillo y BezunarteaValencia, 2020). 
Tabla 1. Categorías empleadas para el estudio cuantitativo de los temas en campaña.

\begin{tabular}{|c|c|}
\hline Temas & Descripción \\
\hline Cambio político & $\begin{array}{l}\text { Publicaciones que versan sobre la necesidad de desarrollar } \\
\text { una alternativa en Galicia al PPdeG. }\end{array}$ \\
\hline $\begin{array}{l}\text { Cuestiones de } \\
\text { género }\end{array}$ & $\begin{array}{l}\text { Mensajes que hacen referencia a políticas de género y otras } \\
\text { estrategias para conseguir la igualdad real entre hombres y } \\
\text { mujeres. }\end{array}$ \\
\hline Eventos políticos & $\begin{array}{l}\text { Alusiones a actos presenciales, como mítines o debates } \\
\text { electorales. }\end{array}$ \\
\hline Economía & $\begin{array}{l}\text { Publicaciones sobre cuestiones económicas como paro, } \\
\text { subsidios o industria. }\end{array}$ \\
\hline Covid-19 & $\begin{array}{l}\text { Mensajes acerca de la pandemia de Covid- } 19 \text {, como sus } \\
\text { efectos sanitarios o educativos, dejando de lado la vertiente } \\
\text { económica. }\end{array}$ \\
\hline $\begin{array}{l}\text { Identidad nacional } \\
\text { gallega }\end{array}$ & $\begin{array}{l}\text { Referencias a Galicia como sujeto político diferenciado y los } \\
\text { aspectos relacionados con esta identidad propia. }\end{array}$ \\
\hline Otros & $\begin{array}{l}\text { Mensajes que no se pueden clasificar en las categorías } \\
\text { anteriores. }\end{array}$ \\
\hline
\end{tabular}

Asimismo, se valora el impacto de la campaña digital a través de las posibilidades de interacción que brinda cada red social. En Twitter se recogen las cifras de retuits y favoritos, en Facebook los comentarios y "me gusta", y en Instagram se recaban variables similares a las de Facebook. Se trata de una manera sencilla de conocer el interés que despiertan los mensajes electorales lanzados, si bien esta atención generada presenta la limitación de circunscribirse a un colectivo sesgado y no representativo de la sociedad como son los usuarios de redes sociales.

El corpus está formado por los mensajes propios publicados en las tres redes sociales seleccionadas por el BNG (perfiles nacionales) y Ana Pontón, excluyendo fórmulas de difusión de contenido ajeno como los retuits o las acciones de compartir en Facebook. Como fecha de recogida de datos se establece la campaña electoral (26 de junio-10 de julio de 2020) y los tres días posteriores a los comicios (13, 14 y 15 de julio), para conocer posibles reacciones a los resultados.

El procedimiento de análisis se ejecuta de manera manual para Facebook e Instagram, mientras que la recogida de tuits se efectúa mediante Twitonomy, que permite recabar de manera automática todo lo publicado en un perfil de Twitter. La muestra total está compuesta de 901 mensajes, repartidos de la siguiente forma: 478 en Twitter, 281 Facebook y 142 Instagram. Todos ellos son analizados para el estudio cuantitativo de carácter temático, mientras que 6 se seleccionan para una aproximación discursiva.

Los detalles de las cuentas estudiadas por cada red social son:

- Twitter. BNG (@obloque) y Ana Pontón (@anaponton).

- Facebook. BNG (Bloque Nacionalista Galego - @obloque)y Ana Pontón (*es cuenta de usuario, no página).

Instagram.BNG (@o_bloque) y Ana Pontón (@ana_ponton). 
Por otro lado, para el estudio de las redes sociales es también pertinente emplear métodos etnográficos, que observen y expongan de manera concienzuda los elementos que componen la realidad virtual (Sádaba Rodríguez, 2012). Con el fin de explorar la configuración de las estrategias de campaña se desarrolla un análisis cualitativo de índole discursiva sobre varios ejemplos significativos de la muestra, extraídos de las tres redes sociales. El criterio de selección utilizado es su carácter representativo, a lo que se añade su vinculación con los tres principios políticos observados como propios del BNG. Se estudian cuatro elementos básicos del discurso: orden y forma, sentido, estilo y retórica (Van Dijk, 2000). El objetivo es proporcionar así las relaciones internas y externas que se producen entre las piezas comunicativas, que pertenecen a la esfera digital.

En cuanto a la descripción de las categorías discursivas aplicadas, la variable "orden y forma" analiza la distribución de los mensajes. En cambio, "sentido"se refiere a interpretar cuál era el objetivo del emisor, mientras que "estilo" alude al grado de formalidad, algo que se debe modular para llegar al público joven que votó mayoritariamente al BNG. Por último, la retórica cita a un género particular de gran capacidad expresiva para convencer al receptor a realizar una acción (voto), objetivo prioritario de toda comunicación electoral.

\section{Resultados}

\subsection{Oferta temática en redes sociales}

El corpus asciende a diferentes cifras en función de la red social, aunque se observa que en numerosas ocasiones los mensajes repiten contenido entre ellos. Exponemos seguidamente la distribución de los mensajes por perfiles:

- Twitter: 77 tuits de Ana Pontón y 401 del BNG.

- Facebook: 43 publicaciones de Ana Pontón y 238 del BNG.

- Instagram: 26 publicaciones de Ana Pontón y 116 del BNG.

Como se puede observar, la actividad de las cuentas del partido es mucho mayor que las de la candidata, un hallazgo conforme a la fuerte consolidación territorial de la formación (Elias, 2009). Hay que tener en cuenta las diferencias entre los perfiles: a 12 de julio de 2020, Ana Pontón poseía 27.200 seguidores en Twitter, 12.479 en Facebook y 10.700 en Instagram, mientras que el BNG contaba con 51.400 en Twitter, 29.892 seguidores en Facebook y 18.900 en Instagram.

El carácter cuantitativamente limitado de la muestra aportada por Pontón, unido a las similitudes observadas en el comportamiento digital del BNG con su líder, nos llevan combinar los datos de ambos para el análisis de contenido. Se pretende obtener así una panorámica de su comunicación. Por redes sociales, en Twitter se aprecia una preferencia por los eventos de campaña (31\%) y el cambio político (29,7\%), ubicados en un nivel similar y seguidos a cierta distancia por la identidad nacional gallega como tema y el Covid-19 (ver Tabla 2).

Por tanto, la acción del nacionalismo gallego en Twitter ha girado en torno a los eventos de campaña (ver Imagen 1) y el cambio político (ver Imagen 2). El ejemplo proporcionado referido a los actos presenciales muestra la conexión con el territorio a través de un 
mitin en Santiago de Compostela, incorporando además personalización de la política en la mención de Pontón a su hija, un rasgo también apreciable en la Imagen 2 que replica el cartel enfocado en Obama como candidato y su Yes, we can.

Tabla 2. Distribución de las publicaciones en Twitter, Facebook e Instagram según su temática (\%). *En negrita datos considerados de interés analítico.

\begin{tabular}{|l|c|c|c|}
\multicolumn{1}{l|}{} & $\begin{array}{c}\text { Ana Pontón + BNG } \\
\text { (Twitter) }\end{array}$ & $\begin{array}{c}\text { Ana Pontón + BNG } \\
\text { (Facebook) }\end{array}$ & $\begin{array}{c}\text { Ana Pontón + BNG } \\
\text { (Instagram) }\end{array}$ \\
\hline Cambio político & $\mathbf{2 9 , 7}$ & 14,7 & $\mathbf{7 , 8}$ \\
\hline Cuestiones género & 5,3 & 3,9 & $\mathbf{1 0 , 2}$ \\
\hline Eventos políticos & 31 & 61,6 & 44,5 \\
\hline Economía & 3,9 & 3,4 & $\mathbf{1 4 , 3}$ \\
\hline Covid-19 & 9,3 & 2,1 & 1,1 \\
\hline $\begin{array}{l}\text { Identidad nacional } \\
\text { gallega }\end{array}$ & 10,7 & 4,4 & $\mathbf{1 2 , 4}$ \\
\hline Otros & 10,1 & 9,9 & 9,7 \\
\hline
\end{tabular}

Imagen 1. Tuit de Ana Pontón sobre un acto en Santiago de Compostela.

Ana Pontón

@anaponton

Emoción en Compostela, a cidade que elexín para vivir e onde naceu a miña filla. Imos facer historia

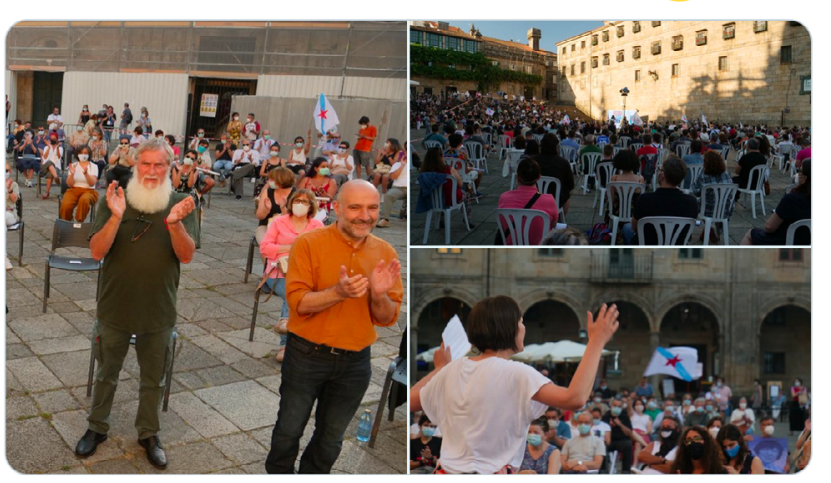

Imagen 2. Tuit de Ana Pontón acerca del cambio gallego.

\section{Ana Pontón}

@anaponton

Que luxo contar co talento de @lidiacao_que me retratou deste xeito $\because$.... e si, o \#CambioGalego é posíbel se nos mobilizamos e concentramos na papeleta do BNG toda a rebeldía e inconformismo que hai no País \#UnhaNovaGaliza Traducir Tweet

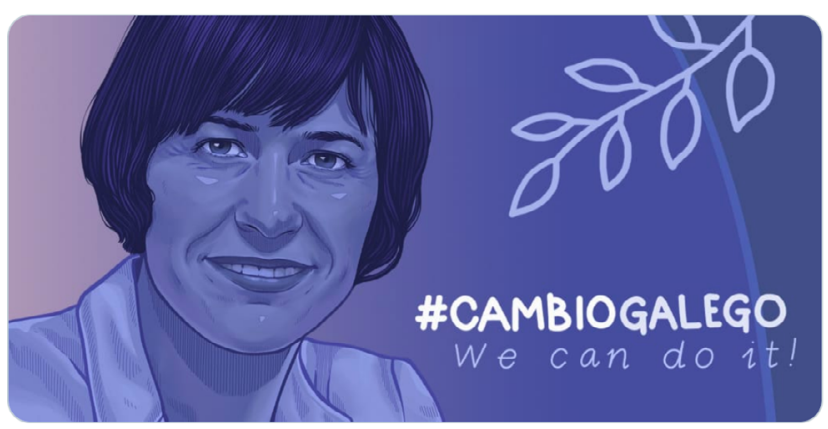

Con respecto a Facebook e Instagram, los mensajes del nacionalismo gallego se encuentran más centrados en eventos políticos (ver Tabla 2). Los perfiles en estas redes sirven como canales para anunciarlos, pero también para reflejar posteriormente el "éxito" de estos actos, a pesar de las limitaciones impuestas por la pandemia. Las mayores diferencias radican en las alusiones a propuestas programáticas sobre género, economía e identidad gallega, que resultan superiores en Instagram mediante fotografías con texto que resumen el programa del BNG.

Los mensajes dedicados a exponer eventos políticos también muestran una clara personalización en torno a la figura de Ana Pontón. En el caso de Instagram puede servir como prueba una publicación de la propia líder sobre un acto en Tomiño (Pontevedra), en el que muestra una camiseta que le han regalado por su reciente maternidad (ver 
Imagen 3. Publicación de Pontón en Instagram tras un mitin en Tomiño (Pontevedra).

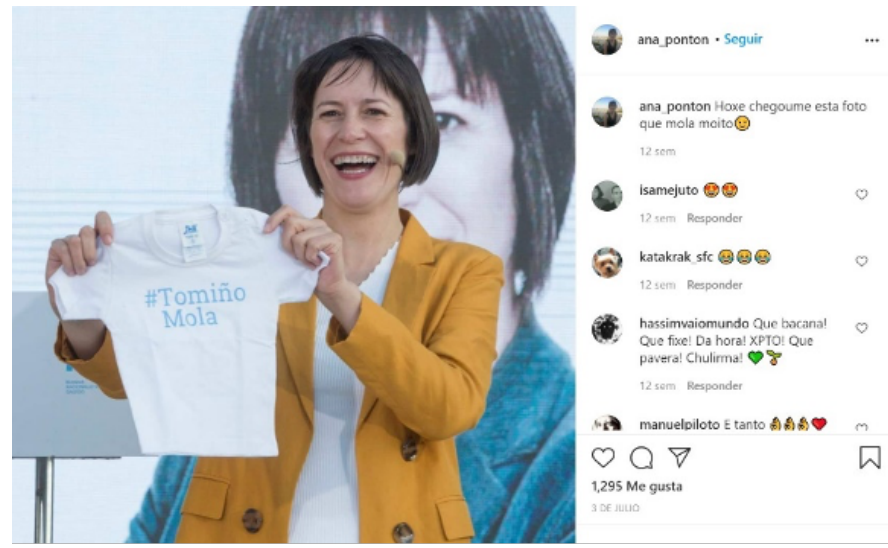

Imagen 4. Publicación del BNG en Facebook informando de un acto público en A Coruña.

bif BNG - Bloque Nacionalista Galego 0

0 de julio - 3

"Quen teña honra que me sigA", dixo María Pita. Pois iso, agardámoste na praza coruñesa adicada a esta muller valente para pechar a campaña electoral na que faremos historia, contigo. Ás 20h. Vémonos!

Ilustración de Bruno Lopes Teixeiro. Novamente, grazas!

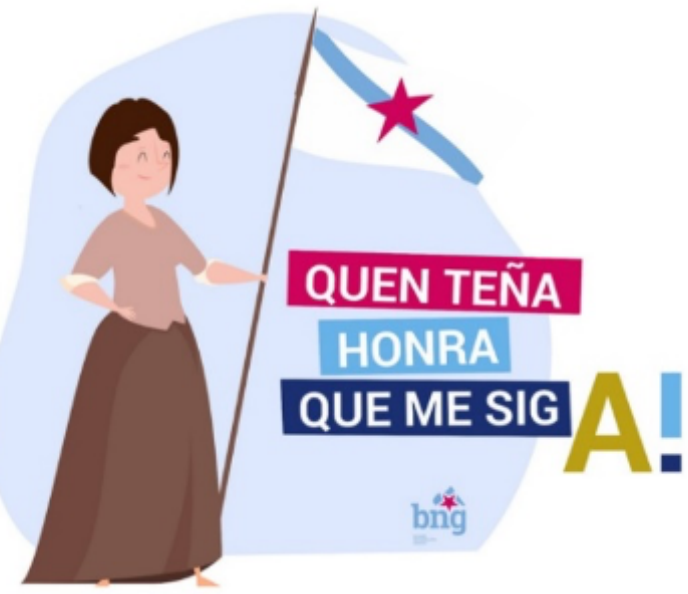

Imagen 3). Esta tendencia es aplicada asimismo por el BNG, como se observa en una publicación de Facebook que anuncia un mitin en A Coruña con una caricatura de Pontón y el lema Quen teña honra que me siga (quien tenga honra que me siga), atribuido a la heroína coruñesa María Pita. Se identifica de esta manera a la candidata nacionalista con una de las mujeres más importantes de la historia de Galicia (ver Imagen 4).

En lo relativo al impacto de los mensajes difundidos en campaña por el BNG y su líder, los datos deben ser interpretados con cautela porque los mecanismos de interacción son distintos entre redes sociales. Destaca el elevado volumen de feedback en Instagram, la red social preferida por los jóvenes, con una media que roza los 1.012 "me gusta" y los 10 comentarios en la cuenta de Pontón, mientras que las cifras del BNG Ilegan a la mitad: 419 "me gusta" y 5 comentarios. Estos resultados reflejan el buen funcionamiento de los liderazgos en la red por excelencia para la imagen.

Esta personalización se repite en Twitter, obteniendo Pontón una media de 121 retuits y 562 favoritos, por los 25 retuits y 39 favoritos de la cuenta

del partido. En cuanto al volumen de interacción por ítems, brindado únicamente para Twitter por el valor de esta red social para la comunicación política, la conjunción de las cifras de Pontón y el BNG evidencia que no hay una correlación perfecta entre los temas preferidos de campaña y aquellos que obtienen una mayor interacción (ver Tabla 3), como es el caso del Covid-19. En cambio, los eventos políticos sí fomentan una atención acorde a su priorización, con porcentajes elevados por encima de las 150 retuits, siendo además mensajes con imágenes y vídeos, que suponen los más virales según la literatura (López-Meri, Marcos-García y Casero-Ripollés, 2017).

Frente a esta tendencia, en Facebook sucede lo contrario, ya que es la cuenta del BNG la que ligeramente genera una mayor atención. El perfil nacionalista tiene 20 comentarios y 212 "me gusta", un dato algo superior al de su candidata: 16 comentarios y 201 "me gusta" de media. En el conjunto de la muestra se aprecia que su líder sí responde en ocasiones a estos mensajes de los ciudadanos, algo inapreciable en los perfiles de la formación. 
Tabla 3. Promedio de retuits por volumen de interacción de acuerdo con su temática (\%). *En negrita datos considerados de interés analítico.

\begin{tabular}{|l|c|c|c|}
\multicolumn{1}{l|}{} & $0-49$ & $50-149$ & Más de 150 \\
\hline Cambio político & 12,3 & 16,8 & 4 \\
\hline Cuestiones género & 4,8 & 0 & 2,4 \\
\hline Eventos políticos & $\mathbf{4 8}$ & 18 & $\mathbf{3 8 , 4}$ \\
\hline Economía & 10,9 & 1,2 & 0 \\
\hline Covid-19 & 3,6 & 28,4 & $\mathbf{3 6}$ \\
\hline Identidad nacional gallega & 9,6 & 22,4 & 19,2 \\
\hline Otros & 10,8 & 13,2 & 0 \\
\hline
\end{tabular}

A la vista de lo anterior, se estima una preponderancia de los liderazgos en Instagram y Twitter. Por el contrario, los usuarios de Facebook parecen proclives a aproximaciones partidistas. Esta red social, que disfruta de más personas registradas que cualquiera otra en España, tiene un funcionamiento democrático que encaja mejor con la lógica de los partidos (Valera-Ordaz, 2019). En cualquier caso, los datos se restringen al período electoral estipulado por esta investigación, observando durante la misma comentarios positivos y moderados, con la excepción de un único mensaje de apoyo a EH Bildu para las Elecciones al Parlamento Vasco que suscitó algunos comentarios negativos.

\subsection{Análisis discursivo}

Para el análisis discursivo se toman 2 casos de interés por cada una de las estrategias identificadas como características de la campaña del BNG (personalización, transversalidad y capilaridad), hasta un total de 6 mensajes estudiados de manera cualitativa. Consideramos que estos ejemplos pueden servir de acercamiento para conocer el valor discursivo de las publicaciones difundidas por el nacionalismo gallego, puesto que sus rasgos han sido observados con asiduidad en la muestra.

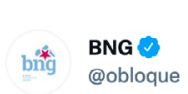

Imaxinalas é o primeiro paso para facer que moitas cousas sucedan. Imaxínao agora. E fagamos que suceda o 12 de xullo. @anaponton Presidenta $\mathrm{O}$. Súmaste?

Traducir Tweet

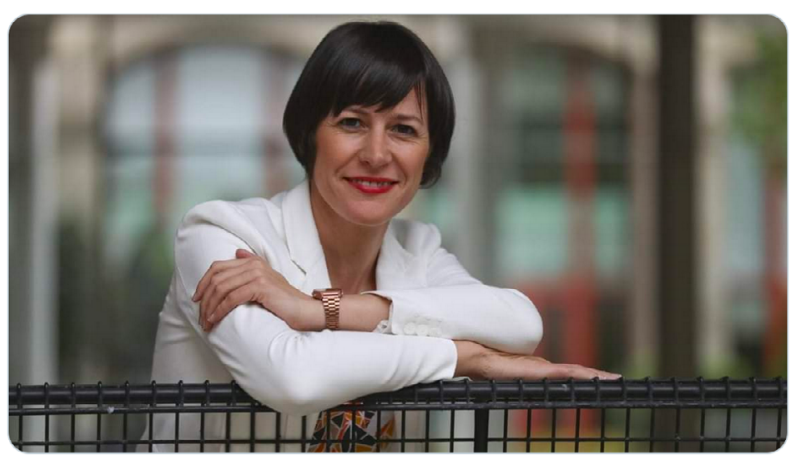

Imagen 5. Tuit del BNG animando a apoyar a Ana Pontón como presidenta.

\section{Personalización}

La personalización como eje de la campaña es algo presente en el propio perfil de Twitter del BNG. En la imagen 5 se expone en un tono positivo que imaginar supone el primer paso para que las cosas sucedan. El mensaje se organiza mediante frases cortas e incluso imperativas como imaxínao agora (imagínalo ahora), que buscan conectar de manera directa con el receptor. Esto hace que el sentido del tuit apele a la movilización del voto, con una pregunta retórica al final - súmaste (¿te sumas?)que incide en ese fin. Es la audiencia la que debe dar el siguiente paso de imaginar el cambio y hacerlo posible. 
El estilo es sencillo y desenfadado, con un corazón propio de la conversación digital y que aquí incorpora el azul corporativo del BNG. La pregunta final posee asimismo valor retórico, haciendo responsable al receptor y vinculando el cambio político con la idea de Ana Pontón como presidenta, una referencia femenina que se inserta en el tuit. El mensaje se acompaña de una sonriente Pontón en primer plano.

El concepto de personalización en el uso de redes sociales con finales electorales alude a un tipo de campaña más centrada en el candidato que en el partido al que representa (Graham, Jackson y Broersma, 2018). La estrategia del BNG emplea conceptos-fuerza como A Presidenta (La Presidenta), que apelan a que Pontón supone una candidata mujer, conectando con reivindicaciones feministas. Dicha personalización resulta aún más evidente en el perfil en Twitter de la candidata, aunque la literatura indica una preferencia general por Facebook para el marketing electoral (Enli y Skogerbø, 2013).

En el mensaje aportado de la cuenta de la candidata en Twitter (ver Imagen 6), se dispone de una breve oración enunciativa sobre el contenido del vídeo, en el que Ana Pontón expone los motivos que la llevaron a entrar en política. La líder nacionalista alude a la cocina de su casa, lugar central en los hogares del rural gallego y que tiene una fuerte relación con la identidad propia. Esta referencia a sus razones personales constituye una práctica clásica de la comunicación política, dirigida a transmitir confianza y honestidad en torno a la candidata, en consonancia con otras acciones comunicativas recientes orientadas a la imagen del individuo (Lalancette y Raynauld, 2019).

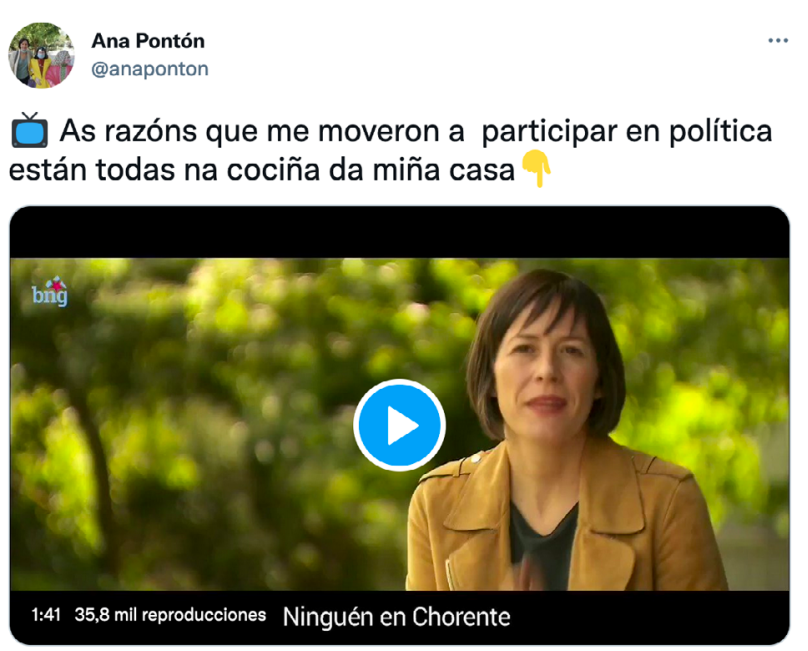

Imagen 6. Tuit de Pontón contando las razones que la impulsaron a participar en política.
El contenido del vídeo sigue un orden secuencial, haciendo un repaso a la infancia de Pontón en la aldea de Chorente (Sarria, Lugo) y cómo el ejemplo de su madre y abuelas le hicieron tomar conciencia política. Aparece así una nueva referencia al ámbito de la mujer, antojándose el feminismo como central en su estrategia política. El estilo es directo y en primera persona, dotado de un sentido que busca conectar a Pontón con la mayoría de la sociedad de Galicia que, aunque no viva en el rural, sí tiene sus raíces en él. Por tanto, la líder nacionalista se presenta como una gallega más, que imbrica su acción política con lo aprendido en la aldea para identificarse de manera clásica con el electorado.

\section{Transversalidad}

Dentro de la estrategia de personalización, que resulta apreciable en otras publicaciones del estudio cualitativo-discursivo, se produce también una tendencia a cierta transversalidad, que la literatura denomina como "flexibilidad ideológica" (Manucci y Amsler, 2017). Pontón se mostró flexible en el eje centralismo-independencia que ha caracterizado históricamente al BNG, pero también en el eje derecha-izquierda, puesto que esta investigación no ha observado mensajes con fuerte carga ideológica. De esta forma, el discurso resulta fácilmente adaptable, en especial a los jóvenes. Como muestra, en la imagen 7 Pontón comparte en su cuenta de Facebook una caricatura suya semejante 
a los personajes de la serie As bolas do dragón (Bola de Dragón), muy popular entre las generaciones que tuvieron su infancia entre las décadas de 1980 y 1990.

Imagen 7. Post de Ana Pontón en Facebook referente a su figura y la serie Bola de Dragón.

Ana Pontón

9 de julio $\cdot \Theta$

Chulisimo, máis porque fun moi fan da serie, As bólas do Dragón $\bullet$

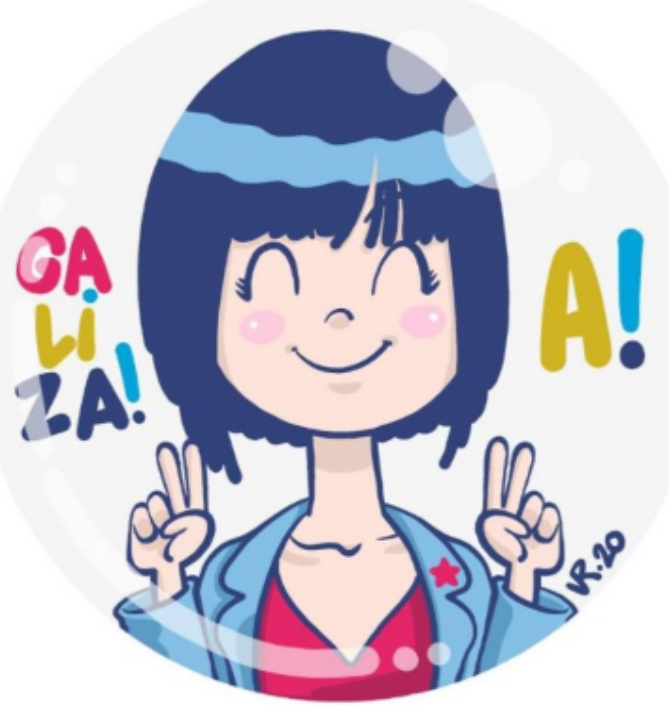

La imagen incorpora la palabra Galiza (topónimo de Galicia en gallego habitual para el nacionalismo) en los colores empleados por el BNG para la campaña, así como un pin de la estrella roja que forma parte de la simbología de la formación. El texto previo es breve y posee un adjetivo calificativo "chulísimo", que refuerza el contenido posterior sobre que la candidata era fan de la serie, sin menciones a cuestiones ideológicas. De este mensaje se deduce un sentido que trata de brindar una percepción juvenil de Pontón, con un estilo ligero dotado de corazones, uno de ellos aplicando el color corporativo del BNG.

El Ilamamiento a la juventud es también detectable en Instagram, que constituye la red social con un público de menor edad en España (Nielsen et al., 2020). La imagen

8 muestra una publicación del BNG con una declaración en vídeo de una chica desde las calles de Ordes (A Coruña). En el clip audiovisual la joven comenta que quiere vivir en un país moderno y justo, en el que no haya que emigrar, y que para ello es necesario llevar a cabo un cambio gallego y dirigido por la gente de la tierra, lo que asocia al BNG.

La formación nacionalista añade un breve texto al vídeo, pidiendo que no se pierda ningún voto, lo que supone hacer hincapié en la movilización de la juventud. Este es el principal sentido del mensaje. El orden de la exposición es de menos a más, tanto en el tono del clip que se focaliza cada vez más en el rostro de la protagonista, como en el mensaje escrito que termina con los hashtags \#CambioGalego \#AnaPresidenta,

Imagen 8. Publicación del BNG en Instagram solicitando el voto.
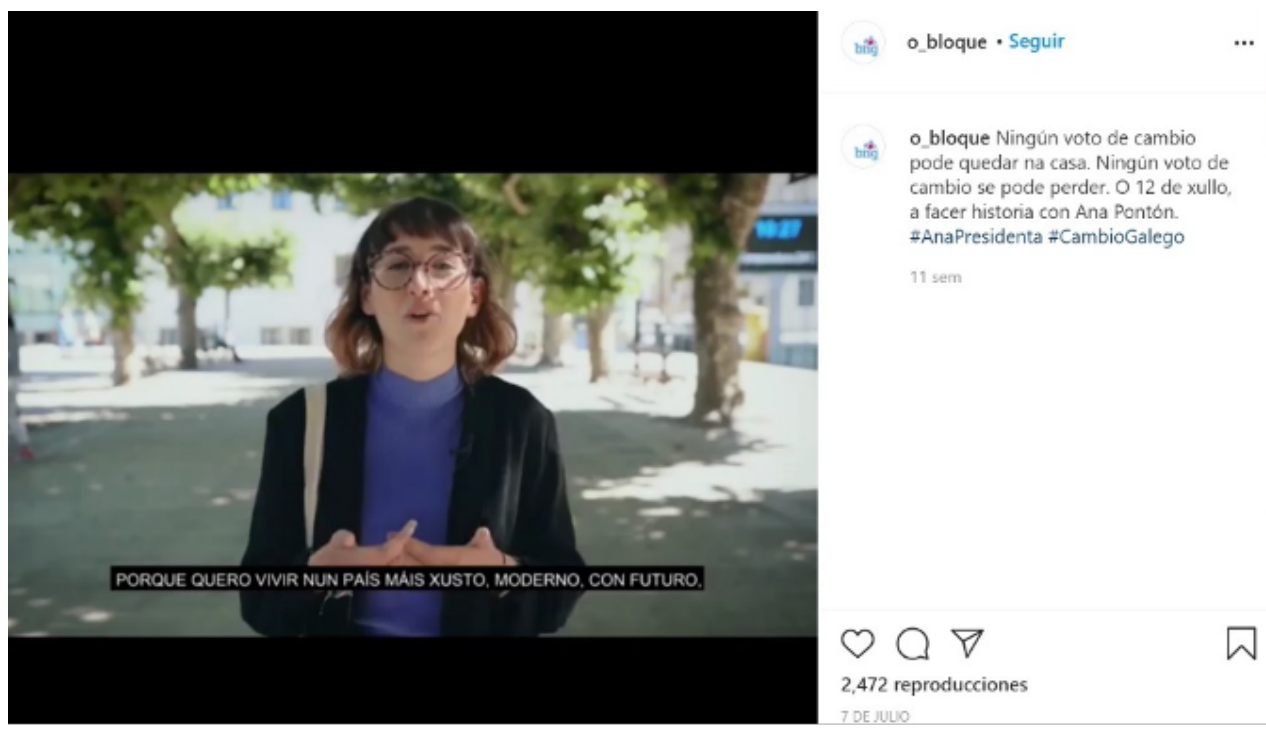
recalcando la idea de una presidencia en femenino. El estilo empleado es sencillo y dotado de lenguaje juvenil en el vídeo, adoptando una temática de hacer historia tras exponer una serie de demandas comunes entre la juventud gallega sobre la falta de oportunidades que trascienden los debates centro-periferia e izquierda-derecha.

El BNG también contó en la campaña con vídeos en Youtube sin aparente dimensión ideológica, caso de "Este país" con más de 8.000 reproducciones, que presentaba cantando distendidamente a algunos de los candidatos de las listas del partido. Este uso de los vídeos musicales es muy habitual desde la llegada de Pontón, con audiovisuales como "Nao e Mini: O soño necesario para un soño" (2016), "Quen nos representa!" (2016), o los más virales "Segue cara adiante" (2018) y "Sumar por Galiza" (2018).

\section{Capilaridad}

Como se ha podido observar hasta ahora, la campaña digital del BNG para los comicios gallegos de 2020 contiene numerosas menciones a localidades, ya sean ciudades, pueblos o aldeas, en consonancia con la dispersión geográfica en Galicia. Precisamente, uno de los rasgos que la literatura cita para este partido es su capilaridad en el territorio (Lois Barrio, 2007). Un ejemplo se encuentra en la imagen 9, de la cual se analiza su dimensión discursiva.

Imagen 9. Tuit de Pontón acerca de un evento público en Moaña (Pontevedra).

Ana Pontón

@anaponton

En \#Moaña volveu pasar, grazas por todo o apoio

O \#12X faremos historia cunha muller PresidentA e coas mans libres para defender Galiza Traducir Tweet

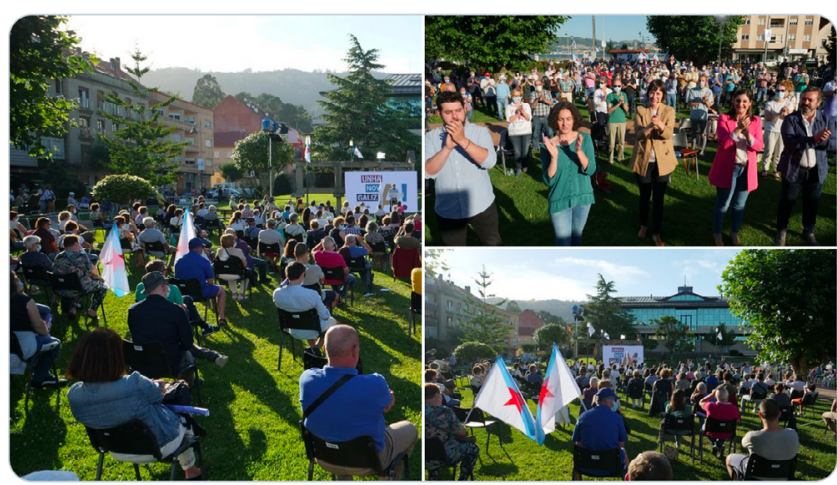

El tuit de Pontón se estructura en torno a dos frases. La primera agradece el apoyo y realiza una elipsis sobre Moaña, dando a entender que en esta villa se ha repetido la gran asistencia a un mitin ya vivida en otros puntos de la comunidad autónoma. Por su parte, la segunda oración habla de hacer historia el día de las elecciones. El sentido del mensaje es informar de lo sucedido en un acto público y apelar a la movilización, a través de varias imágenes que atestiguan el nivel de apoyo.

El estilo del texto es positivo y se ajusta a los principios de Twitter, utilizando hashtags y emojis positivos, entre los

que aparecen de nuevo dos corazones. El tuit desarrolla una retórica historicista ya apreciada, así como referencias al valor feminista de una mujer presidenta que de verdad defenderá los intereses de Galicia. Pontón conecta este valor de hacer historia con una pequeña localidad gallega como Moaña.

Por otro lado, el BNG en Facebook comparte publicaciones de sus agrupaciones locales, que suelen contar con perfiles en esta red social donde informan del transcurrir de la campaña. Ese es el caso de la imagen 10, en la que el BNG de Cambados expone la visita de Ana Pontón a un grupo de mariscadoras. Más allá de que la imagen denota cierta personalización, la forma del mensaje pasa por una oración larga, que relaciona la importancia del sector con la necesidad de un gobierno comprometido como el que podría protagonizar el nacionalismo gallego. 
Imagen 10. Publicación del BNG de Cambados sobre la visita de Pontón a unas mariscadoras.

\section{Bng Cambados}

8 de julio $\cdot 9$

Hoxe a nosa portavoz nacional estivo coas mariscadoras no noso concello, un básico sector para Cambados e para Galiza que precisa dun goberno comprometido

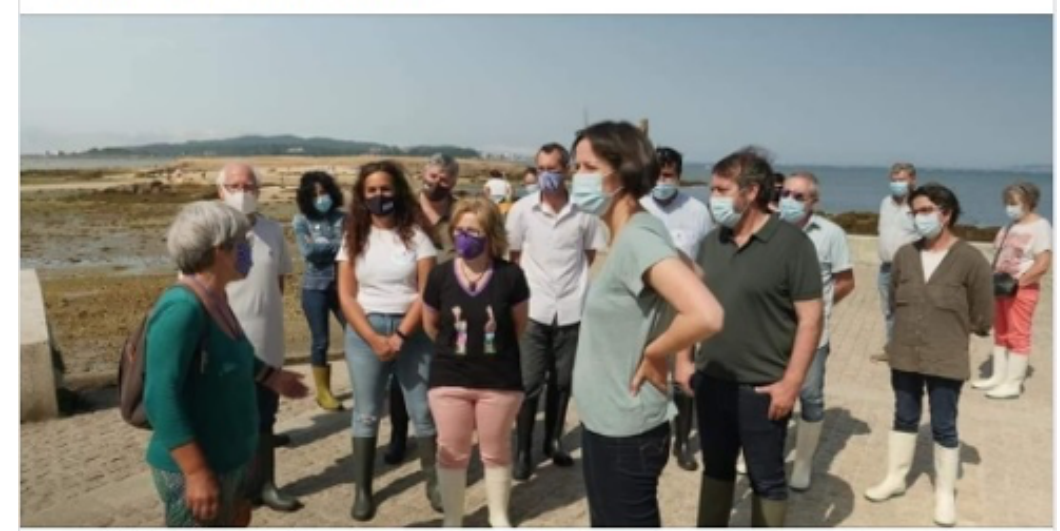

El estilo de la publicación es clásico, sin figuras retóricas, y probablemente suponga la pieza más crítica con el actual gobierno de la Xunta de las aquí analizadas, al dejar entrever de forma velada que las demandas del sector del mar no están cubiertas. El sentido de este mensaje se orienta a transmitir una presencia de la candidata a pie de terreno, una actividad que las agrupaciones locales del BNG se encargan de difundir.

\section{Conclusiones y discusión de resultados}

Teniendo en cuenta el material analizado, ofrecemos las siguientes conclusiones a modo de respuestas a las preguntas de investigación:

1. En relación a la primera cuestión sobre cuáles son los temas abordados por el BNG y Ana Pontón en redes sociales, la agenda temática es plural, pero los eventos políticos constituyen el ítem que vertebra el discurso en campaña en el análisis conjunto de las cuentas del BNG y Ana Pontón. También se alude al cambio político y a diferentes temas programáticos como políticas de género, economía e identidad nacional gallega, con diferencias en cuanto a volumen entre las tres redes sociales analizadas. Llama la atención que, en una situación de crisis sanitaria, las referencias a la pandemia sean escasas.

2. Con respecto al calibre del impacto cuantitativo de los mensajes distribuidos en Internet, su alcance difiere en función de las redes sociales. Sobresale la interacción en Instagram -más de 1.000 “me gusta” de media en las publicaciones de Ana Pontón-y en menor medida en Twitter (562 favoritos de media), prevaleciendo los eventos políticos y el Covid-19 como los temas preferidos en esta última red social. En ambos espacios se observa que los perfiles de Pontón generan una mayor atención que las cuentas del BNG. En cambio, en Facebook es la formación nacionalista la que aglutina una cifra más alta de interacción, si bien su volumen de "me gusta" y "comentarios" se revela inferior a las otras dos plataformas.

3. Como tercera contribución, en respuesta a la pregunta de qué estrategias comunicativas diferenciadas se aplican en cada red social, se recoge que el BNG y Pontón en Facebook e Instagram se centran más en eventos públicos, mientras que en Twitter estos actos y el cambio político se sitúan en una posición similar. Además, en Instagram se detecta una mayor variedad de cuestiones programáticas abordadas. En términos de estrategias aplicadas, y en coherencia con los resultados de interacción, se considera que existe una preponderancia de la personalización en Instagram y Twitter. Por su 
parte, la acción en Facebook se revela proclive al partidismo y al principio de capilaridad, con la flexibilidad como trasfondo de todos los mensajes.

4. Por último, en torno a la forma de articulación de los principios observados, se aprecia la presencia de la personalización, transversalidad y capilaridad en las tres redes sociales, funcionando a través de la figura constante de Pontón, ya sean fotografías o caricaturas. Se brinda una imagen cercana y amable de la candidata, para lo que se referencian cuestiones de su vida personal. El estilo es sencillo y fresco, empleando los recursos propios de las redes, algo singularmente perceptible en los emojis de Twitter. La comunicación desarrollada se asemeja en muchos casos a la propia de los jóvenes, que supone un público objeto de varios mensajes. Además, se interpela al receptor para que se sume a un movimiento histórico y feminista, convirtiendo los actos de campaña a lo ancho del territorio en parte de un proceso de cambio más amplio bajo el lema Unha nova Galiza.

Como discusión, cabe señalar el carácter limitado de la muestra, restringido a un período electoral determinado que, no obstante, consideramos que ofrece pistas sobre las dinámicas actuales del nacionalismo gallego. Pese a que las elecciones se celebraron en un contexto influenciado por el Covid-19 y que este tema recibió numerosos retuits, apenas se observan referencias a la pandemia, que entró ligeramente en campaña con el brote en la comarca de A Mariña (Lugo) a principios de julio de 2020. Esto supone una contribución de la presente investigación, mostrando que dicho asunto no fue valorado como de interés electoral por la formación nacionalista, lo cual puede entroncar además con un posible diseño de las estrategias comunicativas previo a la crisis sanitaria.

La estrategia de flexibilidad del BNG puede interpretarse como una vuelta al "proyecto común" ideológico que lo condujo al poder entre finales de los 90 y la década de los 2000 (Máiz, 2003). La formación, centrada en su candidata Ana Pontón, efectuó para las elecciones de 2020 una campaña en positivo, caracterizada por su pragmatismo ideológico. Se abogó en un contexto singular por generar un marco consuetudinario, en el que el medioambiente, las necesidades de los jóvenes o las políticas de género se convirtieron en hilos conductores, con referencias a la candidatura de una mujer, ya que nunca ha habido una presidenta de la Xunta de Galicia.

Hay que tener en cuenta que el BNG se pudo aprovechar en 2020 del colapso de la izquierda rupturista asociada a Podemos en Galicia. En Marea, que aunaba a Podemos con ciertas corrientes galleguistas, acabó consumida en disputas internas en el período 2016-2020. El Bloque Nacionalista Galego parece haber incorporado la comunicación propia de los movimientos sociales que caracterizó a las "Mareas", siguiendo lo observado en otros partidos (Sánchez Duarte y Magallón Rosa, 2020), algo que se vislumbraba impensable para una formación masculinizada y fuertemente ideologizada en la que predominaban los candidatos de avanzada edad (Espinosa y Lema, 2020). Las alusiones a "hacer historia" crearon un frame de cambio político para lograr la adhesión ciudadana, por encima del componente ideológico, en el que jugó un importante rol el feminismo. Buena parte de la personalización en la figura de Pontón se canalizó en la posibilidad de que una mujer llegara al poder, evidenciado en el lema A Presidenta.

Como futuras líneas de investigación, sería de interés conocer si efectivamente el BNG consigue acceder porcentualmente a nuevos votantes, o si estos se limitan a un juego de suma cero dentro la izquierda gallega, sin opciones de arrebatarle al poder al PP- 
deG. Para ello, es necesario evaluar la estrategia de transversalidad en distintos escenarios, dado que ese valor se ha revelado como imprescindible en las mayorías populares y que la campaña analizada tuvo lugar en un contexto especial, determinado por una pandemia. La disputa comunicativa por ese espacio galleguista y moderado puede marcar la acción política regional en los próximos años, en los que habrá que comprobar la evolución de la conversación digital.

\section{REFERENCIAS}

Aleixandre-Benavent, R., Castelló-Cogollos, L. y Valderrama-Zurián, J. C. (2020): "Información y comunicación durante los primeros meses de Covid-19. Infodemia, desinformación y papel de los profesionales de la información", en Profesional de la información, vol. 29, n 4, e290408. DOI: 10.3145/epi.2020.jul.08

Ares, C. (2017): "La oferta electoral del Bloque Nacionalista Galego (BNG) en las elecciones autonómicas", en Revista de Estudios de la Administración Local y Autonómica, $\mathrm{n}^{\circ}$ 6, pp. 55-69. DOI: $10.24965 /$ reala.v0i5.10387

Ares, C. y Rama, J. (2019): "Las elecciones al Parlamento de Galicia (1981-2016): la importancia de la estrategia de transversalidad del PPdeG". En: Gómez, B., Cabeza, L. y Alonso, S. (eds.): En busca del poder territorial. Cuatro décadas de elecciones autonómicas en España. Madrid: Centro de Investigaciones Sociológicas, pp. 303-330.

Blais, A., Gidengil, E., Nevitte, N. y Nadeau, R. (2004): "Where Does Turnout Decline Come From?", en European Journal of Political Research, vol. 43, n² 2, pp. 221-236.

Blanco Casais, M. (2013): "Alternativa Galega de Esquerdas: un actor diferencial en las elecciones gallegas de 2012", en RIPS: Revista de investigaciones políticas y sociológicas, vol. $12, n^{\circ} 3$, pp. 143-161.

Campos-Domínguez, E. (2017): "Twitter y la comunicación política", en El profesional de la información, vol. 26, nº 5, pp. 785-793. DOI: 10.3145/epi.2017.sep.01

Centro de Investigaciones Sociológicas (2020): Preelectoral de Galicia. Tabulación por escala de ideología política (n 3287). Recuperado el 20 de marzo de 2021, de http:// www.cis.es/cis/opencms/ES/NoticiasNovedades/InfoCIS/2020/Documentacion_3287.html

Chadwick, A. (2013): The hybrid media system. Politics and power. New York: Oxford University Press.

Chavero, P. (2013): "Medios de comunicación y redes sociales en las democracias actuales: ¿complementariedad o sustitución? Una aproximación al caso español". En: Cotarelo, R. (ed.): Ciberpolítica. Las nuevas formas de acción y comunicación políticas. Valencia: Tirant Humanidades, pp. 121-146.

Dader, J. L. (2017): “Campañas políticas 'online': La realidad española frente al horizonte internacional de 'tecnocabildeo"'. En: Dader, J. L. y Campos-Domínguez, E. (eds.): $L a$ búsqueda digital del voto. Cibercampañas electorales en España 2015-16. Valencia: Tirant lo Blanch, pp. 11-74.

de Blasio, E. y Selva, D. (2020): "Affective Governance During the COVID-19 Crisis: Building Leadership, Trust, and Good Citizens", en Trípodos, vol. 47, n 1, pp. 67-85. 
Elias, A. (2009): "From Protest to Power: Mapping the Ideological Evolution of Plaid Cymru and the Bloque Nacionalista Galego", en Regional \& Federal Studies, vol. 19, n ${ }^{\circ}$ 4-5, pp. 533-557. DOI: $10.1080 / 13597560903310253$

Enli, G. y Skogerbø, E. (2013): "Personalized campaigns in party-centred politics", en Information, Communication \& Society, vol. 16, $\mathrm{n}^{\circ}$ 5, pp. 757-774. DOI: 10.1080/1369118X.2013.782330

Enli, G. (2017): "Twitter as arena for the authentic outsider: Exploring the social media campaigns of Trump and Clinton in the 2016 US presidential election", en European Journal of Communication, vol. 32, n 1, pp. 50-61. DOI: 10.1177/0267323116682802

Espinosa, J. C. y Lema, M. (13 de julio de 2020): “La generación nacionalista gallega que se cansó de perder". El País. Recuperado el 20 de marzo de 2021 de https://elpais.com/ espana/2020-07-13/la-generacion-nacionalista-que-se-canso-de-perder.html

Esser, F. y Strömbäck, J. (eds.) (2014): Mediatization of Politics: Understanding the Transformation of Western Democracies. Londres: Palgrave Macmillan.

Fernández-Cabana, M., Rúas-Araújo, X. y Alves-Pérez, M. T. (2014): “Psychology, language and communication: Analysis with the tool LIWC of the speeches and tweets from the candidates to 2012 Galician elections", en Anuario de psicología / The UB Journal of psychology, vol. 44, n² 2, pp. 169-184.

García-Ortega, C. y Zugasti-Azagra, R. (2018): "Gestión de la campaña de las elecciones generales de 2016 en las cuentas de Twitter de los candidatos: entre la autorreferencialidad y la hibridación mediática", en El profesional de la información, vol. 27, n 6, pp. 1215-1224. DOI: 10.3145/epi.2018.nov.05

Gómez-Reino, M. (2009): “El nacionalismo minoritario, de la marginalidad al gobierno: la trayectoria del Bloque Nacionalista Galego (1982-2007)", en Papers: revista de sociologia, ${ }^{\circ}$ 92, pp. 119-142.

Graham T., Jackson D. y Broersma M. (2018): "The Personal in the Political on Twitter: Towards a Typology of Politicians' Personalized Tweeting Behaviours". En: Schwanholz J., Graham T. y Stoll P. T. (eds.): Managing Democracy in the Digital Age. Cham: Springer, pp. 137-157.

Igartua, J. J. (2006): Métodos cuantitativos de investigación en comunicación. Barcelona: Bosch.

Jenkins, J.y Nielsen, R. K. (2020): "Proximity, Public Service, and Popularity: A Comparative Study of How Local Journalists View Quality News", en Journalism Studies, vol. 21, n², pp. 236-253. DOI: 10.1080/1461670X.2019.1636704

Jungherr, A. (2016): "Twitter use in election campaigns: A systematic literature review", en Journal of Information Technology \& Politics, vol. 13, n 1, pp. 72-91. DOI: $\underline{10.1080 / 19331681.2015 .1132401}$

Lagares Diez, N., Jaráiz Gulías, E. y Castro Martínez, P. (2020): “La percepción de los debates como factor de decisión en el comportamiento electoral en las Elecciones Generales de abril de 2019", en Revista Latina de Comunicación Social, n 76, pp. 39-58. DOI: $10.4185 /$ RLCS-2020-1436 
Lalancette, M. y Raynauld, V. (2019): “The Power of Political Image: Justin Trudeau, Instagram, and Celebrity Politics", en American Behavioral Scientist, vol. 63, n 7, pp. 888-924. DOI: $10.1177 / 0002764217744838$

Lecheler, S. y Kruikemeier, S. (2016): "Re-evalua-ting journalistic routines in a digital age: A review of re-search on the use of online sources", en New Media \& Society, vol. 18, n 1, pp. 156-171. DOI: $10.1177 / 1461444815600412$

Lois Barrio, M. D. (2007): Lugar y política: el apoyo electoral al Bloque Nacionalista Galego (1977-2002): los casos de Allariz y Fene. (Tesis doctoral). Dirigida por Heriberto Cairo Carou. Madrid: Universidad Complutense de Madrid. Disponible en: https://eprints.ucm. es/8548/ [Consulta: 20 de marzo de 2021].

López-López, P. C., Puentes-Rivera, I. y Rúas-Araújo, J. (2017): “La comunicación política en las elecciones gallegas del 25 de septiembre de 2016: la agenda temática en el debate de la TVG". En: Herrero-Gutiérrez, F. J., Mateos-Martín, C., Toledano-Buendía, S., Ardèvol-Abreu, A. y Trenta, M. (eds.): Del verbo al bit (Cuadernos Artesanos de Comunicación). La Laguna: Universidad de La Laguna, pp. 1431-1460.

López-Meri, A., Marcos-García, S. y Casero-Ripollés, A. (2017): “What do politicians do on Twitter? Functions and communication strategies in the Spanish electoral campaign of 2016", en El profesional de la información, vol. 26, n 5, pp. 795-804. DOI: 10.3145/ epi.2017.sep.02

Máiz, R. (1996): "Nación de Breogán: oportunidades políticas y estrategias enmarcadoras en el movimiento nacionalista gallego (1886-1996)", en Revista de Estudios Políticos, $\mathrm{n}^{\circ}$ 92, pp. 33-75.

Máiz, R. (2003): “Making Opportunities: Contemporary Evolution of Galician Nationalism in Spain (1982-2001)", en Studies in Ethnicity and Nationalism, vol. 3, n² 2, pp. 20-34. DOI: $\underline{10.1111 / j .1754-9469.2003 . t b 00047 . x}$

Máiz, R. y Ares, C. (2018): "The Shifting Framing Strategies and Policy Positions of the Bloque Nacionalista Galego", en Nationalism and Ethnic Politics, vol. 24, n 2, pp. 181 200. DOI: $10.1080 / 13537113.2018 .1457824$

Manucci, L. y Amsler, M. (2018): “Where the wind blows: Five Star Movement's populism, direct democracy and ideological flexibility", en Italian Political Science Review/Rivista Italiana Di Scienza Politica, vol. 48, no 1, pp. 109-132. DOI: 10.1017/ipo.2017.23

Mañas Ramírez, B. (2013): "Más allá de los sondeos: hacia un estudio discursivo de la opinión pública". En: Garrido, A. y Vinuesa, L. (eds.): La Reina del Mundo: reflexiones sobre la Historia de la Opinión Pública. Madrid: TGD, pp. 147-172.

Marín Dueñas, P. P. y Díaz Guerra, A. (2016): "Uso de Twitter por los partidos y candidatos políticos en las elecciones autonómicas de Madrid 2015", en Ámbitos: Revista internacional de comunicación, $\mathrm{n}^{\circ} 32$.

Mazzoleni, G. (2010): La comunicación política. Madrid: Alianza Editorial.

McAllister, I. (2007): “The personalization of politics”. En: Dalton, R. y Klingemann, H. D. (eds.): The Oxford Handbook of Political Behaviour. Oxford: Oxford University Press, pp. 571-588. 
Morales López, E. y Montesano Montessori, N. (2019). “The articulation of 'the people' in the discourse of Podemos and its partners En Marea and En Comú Podem. The dilemma with ethnicity". Comunicación presentada en el Congreso 'Discourse Theory: Ways Forward'. Bruselas, 7-8 de febrero.

Nielsen, R. K., Fletcher, R., Newman, N., Brennen, J. C. y Howard, P. N. (2020): Navigating the 'Infodemic': How People in Six Countries Access and Rate News and Information about Coronavirus. Oxford: Reuters Institute for the Study of Journalism, University of Oxford. Disponible en: https://reutersinstitute.politics.ox.ac.uk/infodemic-how-people-sixcountries-access-and-rate-news-and-information-about-coronavirus [Consulta: 20 de marzo de 2021].

Núñez Seixas, X. M. (2001): “De Breogán a Pardo de Cela, pasando por América: Notas sobre la imaginación del nacionalismo gallego", en Historia Social, n 40 (La Construcción Imaginaria de las Comunidades Nacionales), pp. 53-78.

O'Rourke, B. y Ramallo, F. (2015): “Neofalantes as an active minority: understanding language practices and motivations for change amongst new speakers of Galician", en International Journal of the Sociology of Language, vol. 2015, $n^{\circ} 231$. DOI: 10.1515/ ijsl-2014-0036

Pérez-Curiel, C. y García-Gordillo, M. (2020): “Del debate electoral en TV al ciberdebate en Twitter. Encuadres de influencia en las elecciones generales en España (28A)", en Profesional de la información, vol. 29, n 4, e290405. DOI: https://doi.org/10.3145/epi.2020. jul.05

Rivas-de-Roca, R. (2020): “La configuración del fenómeno ecologista \#FridaysForFuture como proceso de opinión pública digital en España", en Dígitos, n 6, pp. 79-100. DOI: 10.7203/rd.v1i6.162

Rivas-de-Roca, R., García-Gordillo, M. y Bezunartea-Valencia, O. (2020): "The far-right's influence on Twitter during the 2018 Andalusian elections: an approach through political leaders", en Communication \& Society, vol. 33, $\mathrm{n}^{\circ}$ 2, pp. 227-242. DOI: $\underline{10.15581 / 003.33 .2 .227-242}$

Rodríguez-Virgili, J., Jandura, O. y Rebolledo-de-la-Calle, M. (2014): “La personalización de la política en la cobertura mediática: una comparación de las campañas electorales en España y Alemania", en Trípodos, vol. 1, n³ 34, pp. 61-79.

Rosanvallon, P. (2007): La Contrademocracia. La política en la era de la desconfianza. Buenos Aires: Editorial Manantial.

Rúas-Araújo, J. y Quintas-Froufe, N. (2020): “Televisión, audiencias y debates electorales: hacia la multipantalla", en El profesional de la información, vol. 29, n², e290201. DOI: 10.3145/epi.2020.mar.01

Sádaba Rodríguez, I. (2012): “Introducción a la investigación social online”. En: Arroyo Menéndez, M. y Sádaba Rodríguez, I. (coords.): Metodología de la investigación social: técnicas innovadoras y sus aplicaciones. Madrid: Síntesis, pp. 197-216.

Sánchez Duarte, J. M. y Magallón Rosa, R. (2020): “De la diferencia de usos y prácticas a la convergencia. Partidos políticos y movimiento sociales en la sociedad digital". En: Castromil, A. R., Humanes, M. L. y García Tojar, L. (eds.): La comunicación política en la 
era de la mediatización. Salamanca: Comunicación Social, pp. 227-242

Schäfer, A., Roßteutscher, S. y Abendschön, S. (2020): "Rising start-up costs of voting: political inequality among first-time voters", en West European Politics, vol. $43, n^{\circ} 4$, pp. 819-844. DOI: $10.1080 / 01402382.2019 .1638141$

Tenscher, J., Koc-Michalska, K., Lilleker, D. G., Mykkänen, J., Walter, A. S., Findor, A., Jalali, C. y Róka, J. (2016): “The professionals speak: Practitioners' perspectives on professional election campaigning", en European Journal of Communication, vol. 3, $\mathrm{n}^{\circ}$ 2, pp. 95-119. DOI: $10.1177 / 0267323115612212$

Toret, J. (2013): Tecnopolítica: la potencia de las multitudes conectadas. El sistema red 15M, un nuevo paradigma de la política distribuida. Barcelona: IN3, UOC.

Vaccari, C. y Valeriani, A. (2015): "Follow the leader! Direct and indirect flows of political communication during the 2013 Italian general election campaign", en New Media \& Society, vol. 17, n 7, pp. 1025-1042. DOI: $10.1177 / 1461444813511038$

Valera-Ordaz, L. (2019): “Liberal individualist, communitarian, or deliberative? Analyzing political discussion on Facebook based on three notions of democracy", en International Journal of Communication, vol. 13, pp. 1056-1076.

Valera Ordaz, L., Carratalá Simón, A. y Palau Sampio, D. (2017): “La construcción de la agenda en campaña electoral". En: López García, G. y Valera Ordaz, L. (coords.): Pantallas electorales el discurso de partidos, medios y ciudadanos en la campaña de 2015. Barcelona: Editorial UOC, pp. 59-77.

Van Dijk, T. A. (ed.) (2000): El discurso como estructura y proceso: introducción multidisciplinaria. Barcelona: Gedisa.

Varela, M. y Placer, L. (15 de julio de 2020): "El BNG atrae a los menores de 40 años, y el PP arrasa a partir de los 50". La Voz de Galicia. Recuperado el 20 de marzo de 2021 de https://www.lavozdegalicia.es/noticia/elecciones/2020/07/14/reparto-voto-edad-renta-eleccionesgallegas-12-j/00031594746645107613476.htm

Warf, B. y Ferras, C. (2015): "Nationalism, identity and landscape in contemporary Galicia", en Space and Polity, vol. 19, n 3, pp. 256-272. DOI: $\underline{10.1080 / 13562576.2015 .1080425}$ 